\title{
Length Change and Deformation of Powder Injection-Molded Compacts during Solvent Debinding
}

\author{
S.C. HU and K.S. HWANG
}

Solvent debinding is one of the processes widely adopted by the powder injection molding industry. Despite the inherent advantages of short debinding cycles, the low temperature employed, and the low investment in processing equipment, dimensional control is still a challenge to the further promotion of this technology. The objective of this study was to investigate the causes of the tolerancecontrol problems by measuring the in-situ dimensional change and deformation behavior of powder injection-molded (PIM) specimens during debinding, using a self-designed laser dilatometer. Swelling and sagging were found when compacts were immersed in the solvent. Three major factors were found to be responsible for the expansion of the specimens: dissolution of soluble binder into the solvent, reaction between the insoluble binder and solvent, and thermal expansion due to the temperature rise from the solvent bath. The amounts of expansion and sagging were related to the thickness of the sample, the amount of the binder, and the temperature employed. These in-situ measurements on the dimensional change help explain how defects such as slumping, cracking, and distortion come about during debinding and provide some guidelines in selecting processing parameters and in designing binder compositions.

\section{INTRODUCTION}

SOLVENT debinding is one of the most-widely adopted processes in the powder injection molding industry, because of its effectiveness in removing binders from compacts. ${ }^{[1,2,3]}$ The first step in this process is to use solvent to extract soluble binder components from the compact. The remaining insoluble binders are then pyrolyzed or decomposed during a subsequent thermal heating process. ${ }^{[3,4,5]}$ During the solvent extraction step, interconnected pore channels are left behind after soluble binders are dissolved into the solvent. As the solvent-debound compacts are subjected to thermal debinding, decomposed gas forms and escapes into the ambient air through the existing pore channels. Since there is little pressure built up from the gas, this process can, thus, eliminate defects like bubbles, cracks, exfoliation, and pin holes, which usually occur in the straight thermal debinding process. ${ }^{[6]}$ However, some other defects such as cracking, distortion, and slumping are still frequently encountered in solvent debinding. ${ }^{[7-11]}$ These defects have been shown to be related to the swelling and softening caused by the reaction between the solvent and the binders. ${ }^{[7,12,13]}$ Lin and Hwang studied the effects of processing parameters and binder characteristics on the amount of swelling by measuring the in-situ dimensional changes of compacts during debinding. ${ }^{[13]}$ Their results showed that the amount of expansion increases with an increase in the debinding temperature and the amount of insoluble binder and with the decrease in the molecular weight of the solvent and the binder.

These previous studies have indicated that the tolerance control and defects of powder injection-molded (PIM) compacts are closely related to the swelling and softening behavior of binders during solvent debinding. However, few

S.C. HU, Graduate Student, and K.S. HWANG, Professor, are with the Institute of Materials Science and Engineering, National Taiwan University, Taipei 106, Taiwan, Republic of China.

Manuscript submitted September 13, 1999. studies have been reported to date on the details of these phenomena. The purpose of this study was, thus, to further investigate the effects of debinding parameters on the dimensional control of PIM compacts.

\section{EXPERIMENTAL PROCEDURE}

Carbonyl iron powders with an average particle size of $4.6 \mu \mathrm{m}$ were used in this study. The iron's characteristics are shown in Table I. To prepare the feedstock, iron powders were kneaded with $6.5,7$, and 8 wt pct binders, respectively. The binder consisted of $40 \mathrm{wt}$ pct low-density polyethylene (LDPE), $55 \mathrm{wt}$ pct paraffin wax (PW), and $5 \mathrm{wt}$ pct stearic acid (SA). Both PW and SA can be dissolved into heptane, while LDPE cannot; the former and the latter are, thus, categorized as soluble and insoluble binders, respectively. After being kneaded and granulated, the feedstock was molded into rectangular specimens of $2 \times 10 \times 100 \mathrm{~mm}$ in size.

Solvent debinding was carried out by immersing molded compacts in heptane at various temperatures between $27^{\circ} \mathrm{C}$ and $55{ }^{\circ} \mathrm{C}$. The heating rate used was $1{ }^{\circ} \mathrm{C} / \mathrm{min}$. The in-situ dimensional change of specimens during solvent debinding was measured with a self-designed laser dilatometer. The setup of the instrument was modified from the one used previously in Reference 13, and the new setup is shown in Figure 1. The specimen was fixed at the right-hand side, and the specimen could move freely only to the left. To facilitate movement, several alumina rollers were placed underneath the specimen to reduce the friction. Since the laser sensor (N $\Lambda$ IS LM-100, Osaka, Japan) could not be immersed into the solvent bath to directly measure the length change of the specimen, a thin alumina plate was attached to the left end of the specimen, like a periscope, and the displacement of the alumina plate was measured instead.

To analyze the in-situ deformation behavior of compacts during solvent debinding, the setup of the laser dilatometer was modified as shown in Figure 2. The specimen was 
Table I. Characteristics of the Carbonyl Iron Powder Used in This Study

\begin{tabular}{ll}
\hline \multicolumn{1}{c}{ Iron Powder } & \multicolumn{1}{c}{ Characteristics } \\
\hline Designation & $\begin{array}{c}\text { carbonyl iron powder } \\
\text { (CIP-S-1641) }\end{array}$ \\
Supplier & ISP Corp (Wayne, NJ) \\
Average particle size (Fisher) & $4.6 \mu \mathrm{m}$ \\
Shape & spherical \\
Surface area (BET) & $0.77 \mathrm{~m}^{2} / \mathrm{g}$ \\
Density (pycnometer) & $7.542 \mathrm{~g} / \mathrm{cm}^{3}$ \\
Chemistry & \\
C, pct & 0.7156 \\
S, pct & 0.0014 \\
N, pct & 0.7378 \\
O, pct & 0.6871 \\
\hline
\end{tabular}

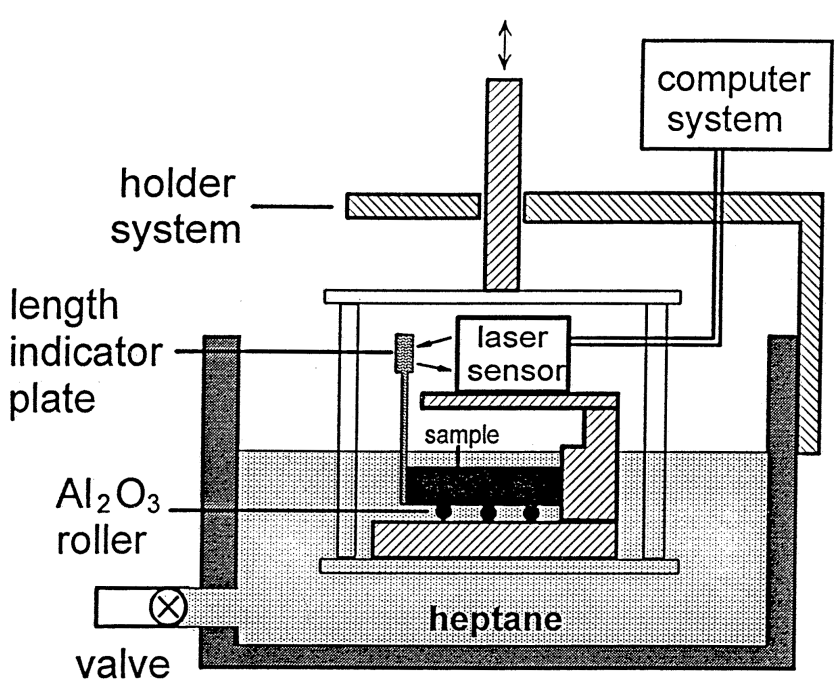

Fig. 1-Setup of the laser dilatometer for measuring the in-situ length changes.

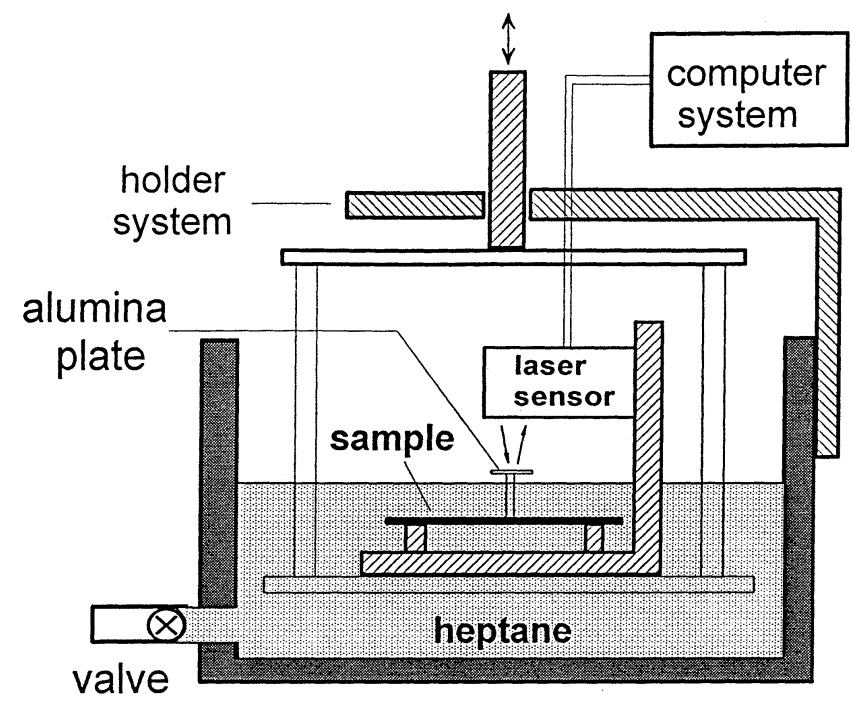

Fig. 2-Setup of the laser dilatometer for measuring the in-situ sagging distances.

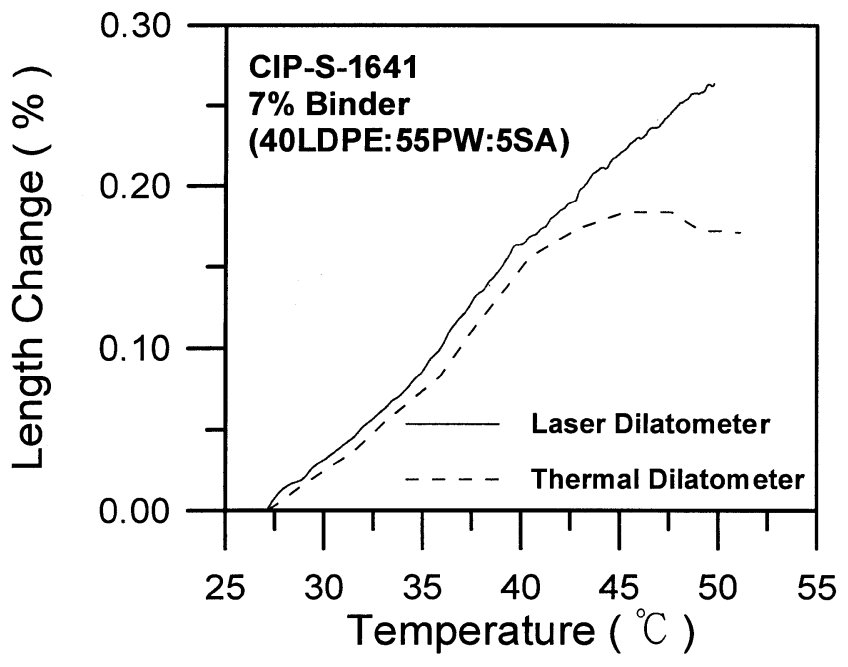

Fig. 3-The thermal expansion curve of specimens measured by using the laser dilatometer and the thermal dilatometer, respectively.

supported by two blocks set $60 \mathrm{~mm}$ apart. A depth-indicator plate made of alumina was attached to the center of the specimen so that as the specimen was immersed in the solvent bath; the in-situ sagging distance of the compact could be detected by the laser sensor. The main advantage of these two instruments is that the dimensions of Compacts are measured by the noncontacting optical method, so that any mechanical contact force incurred by using conventional measuring devices on the softened compact is eliminated.

In addition to the laser dilatometer, a thermal dilatometer (Dilatronic II, Theta Co., Port Washington, NY) was used to measure the amount of thermal expansion of compacts. The values were compared to those measured by the laser dilatometer. To determine the melting point of each pure binder and the mixed feedstock, a differential scanning calorimeter (DSC) (DSC 910, E. I. DuPont de Nemours, Wilmington, DE) was used. The testing was carried out in nitrogen using a heating rate of $10{ }^{\circ} \mathrm{C} / \mathrm{min}$.

\section{RESULTS}

To determine the accuracy of the laser dilatometer, the thermal-expansion coefficient (CTE) of an oxygen-free copper block was measured. The result agreed with the handbook data of $18 \times 10^{-6} \mathrm{~m} / \mathrm{m} / \mathrm{K}$. The thermal-expansion behavior of a PIM compact that contained 7 wt pct binder was then monitored by using a laser dilatometer and a thermal dilatometer, respectively. Figure 3 shows that these two curves had the same trend as the temperature increased from room temperature $\left(27{ }^{\circ} \mathrm{C}\right)$ to $40{ }^{\circ} \mathrm{C}$. The $\mathrm{CTE}$ was $116 \times$ $10^{-6} \mathrm{~m} / \mathrm{m} / \mathrm{K}$. When the temperature was higher than $40{ }^{\circ} \mathrm{C}$, the specimen in the laser dilatometer continued to expand, but the one in the thermal dilatometer started to shrink. This was due to the softening of the compact, as was demonstrated by the DSC tests, which indicated that the melting points of SA, PW, and LDPE in the kneaded feedstock were 43 ${ }^{\circ} \mathrm{C}, 59^{\circ} \mathrm{C}$, and $98{ }^{\circ} \mathrm{C}$, respectively. The softening showed that the small load of $10 \mathrm{gm}$ exerted by the push rod in the thermal dilatometer was enough to cause deformation on the compact at temperatures greater than $40{ }^{\circ} \mathrm{C}$. This also demonstrated the advantage of eliminating the binder's softening effect by using the laser dilatometer. 


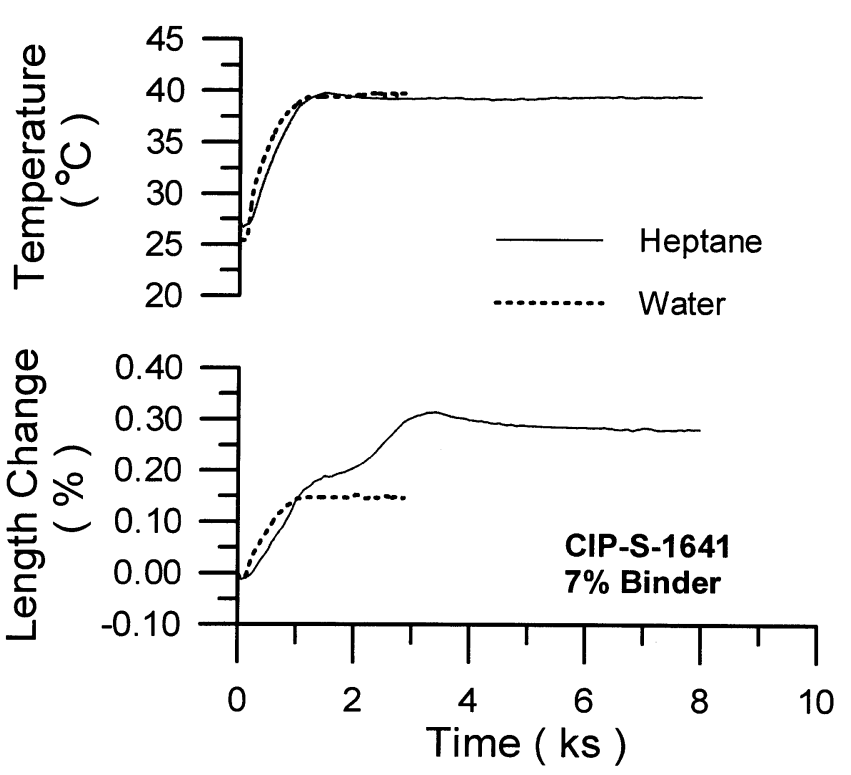

Fig. 4-The changes in temperature and length of PIM specimens immersed in heptane and water, respectively.

After the calibration test, the CTEs of the pure PW, SA, and LDPE, of the mixed binder, and of a solid iron block were measured using the laser dilatometer, and they were $395,275,185,290$, and $11.8 \times 10^{-6} \mathrm{~m} / \mathrm{m} / \mathrm{K}$, respectively. The CTE of the mixed binder is lower than $305 \times 10^{-6} \mathrm{~m} /$ $\mathrm{m} / \mathrm{K}$, which is calculated from the CTEs of PW, SA, and the LDPE, using the rule of mixtures. This suggests that there is intersolubility among the binder components.

\section{A. Length Change}

Figure 4 compares the length change of compacts when immersed in heptane and water, respectively. Both curves expanded during the heating period. As the temperature stabilized at $40{ }^{\circ} \mathrm{C}$, the length of the specimen which was immersed in water also reached equilibrium. However, in heptane, the PIM specimen continued to expand; stabilizing after $5 \mathrm{ks}$. This indicated that there was an interaction between the solvent and the binder.

Figure 5 shows the effect of the debinding temperature on this interaction. At $50{ }^{\circ} \mathrm{C}$, the curve reached a plateau of about 0.42 pct in $2 \mathrm{ks}$. As the temperature decreased to $40{ }^{\circ} \mathrm{C}$ and $27{ }^{\circ} \mathrm{C}$, the amount of swelling decreased. After debinding, the final length of all specimens shows a small amount of shrinkage. It was also observed that the shapes of the curves were different. At $40{ }^{\circ} \mathrm{C}$ and $27{ }^{\circ} \mathrm{C}$, there was a peak at the front section of the plateau, and the magnitude of the peak increased as the debinding temperature decreased. As the debinding time increased, this peak disappeared. This suggested that this additional swelling in the early stage could be related to the amount of PW and SA in the compact, which are soluble in heptane.

To confirm this, a specimen was first immersed in $40{ }^{\circ} \mathrm{C}$ heptane for $18 \mathrm{ks}$ to remove about 90 pct of the $\mathrm{PW}$ and SA. A peak was noticed at $3 \mathrm{ks}$ during this debinding stage, as shown in Figure 6. After $18 \mathrm{ks}$, the specimen was retrieved by lifting it out of the solvent bath and then cooled for 5 $\mathrm{ks}$ at room temperature. The specimen was then reimmersed in the heptane. During the second debinding period, the

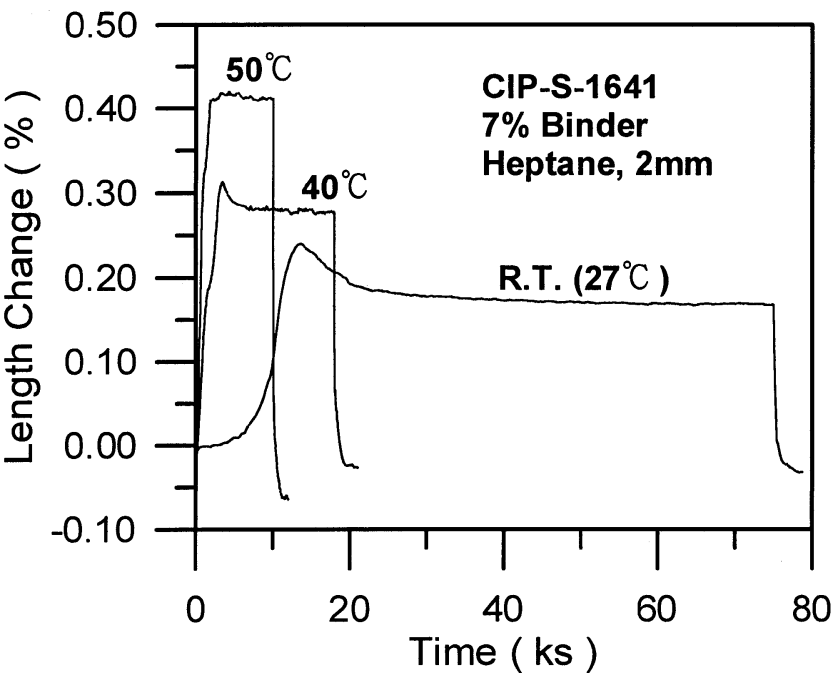

Fig. 5-Effect of temperature on the length change of specimens during solvent debinding.

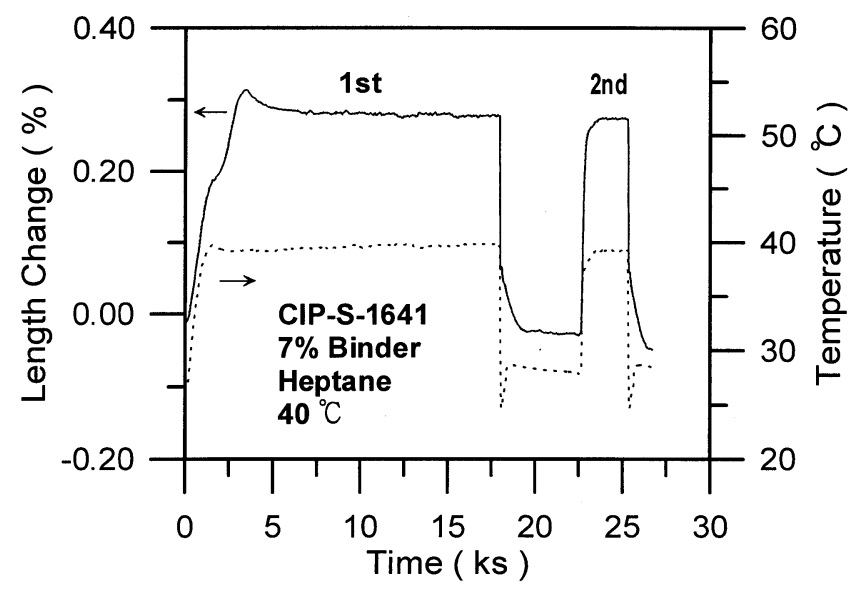

Fig. 6-The peak that was present in the first debinding step disappeared during the second debinding step.

peak disappeared. The final amount of expansion at both debinding steps was about the same, at 0.28 pct. This shows that the peak that was present in the first debinding step was caused by the soluble binder, and the final 0.28 pct expansion was mainly caused by the swelling insoluble binder.

The effect of the binder content on the swelling curve is illustrated in Figure 7. As the binder content increased from 6.5 to $8 \mathrm{wt}$ pct, the amount of expansion increased. This result supports the findings of Lin and Hwang. ${ }^{[13]}$

Another factor that affects the amount of expansion of PIM parts is the thickness. Figure 8 shows that the 4-mmthick specimen needed a longer debinding time than the 2mm-thick specimen to reach the plateau. At $1.5 \mathrm{ks}$ of debinding time, the 2-mm-thick specimen expanded $0.41 \mathrm{pct}$, while the 4-mm-thick specimen expanded only 0.24 pct. It is suggested that the center portion of the thicker specimen restricted the expanding outer section, which had reacted with the solvent more intensely.

\section{B. Sagging}

Although solvent debinding uses a temperature much lower than those used in thermal debinding, some sagging 


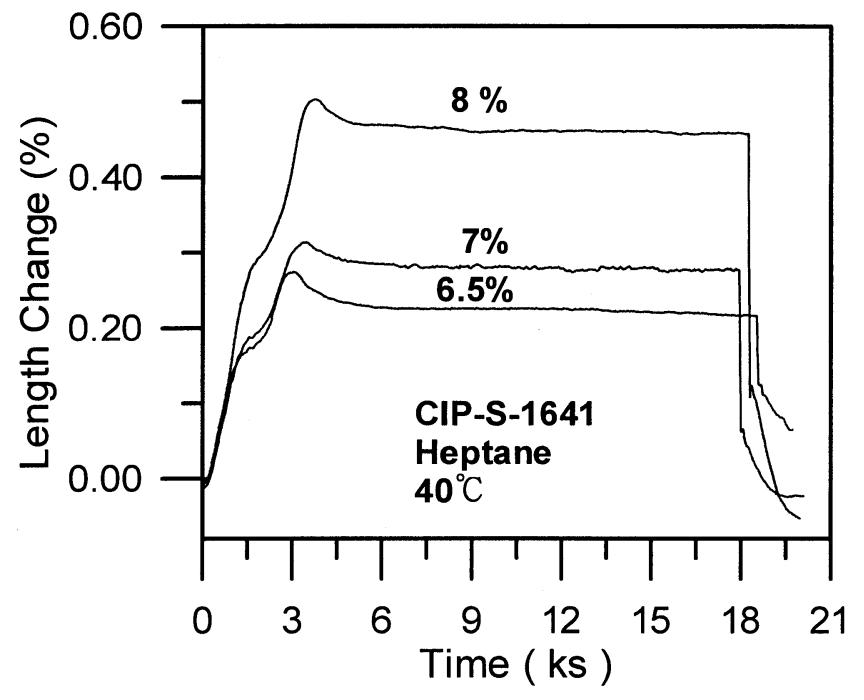

Fig. 7-The amount of expansion increases with the increase of the binder content.

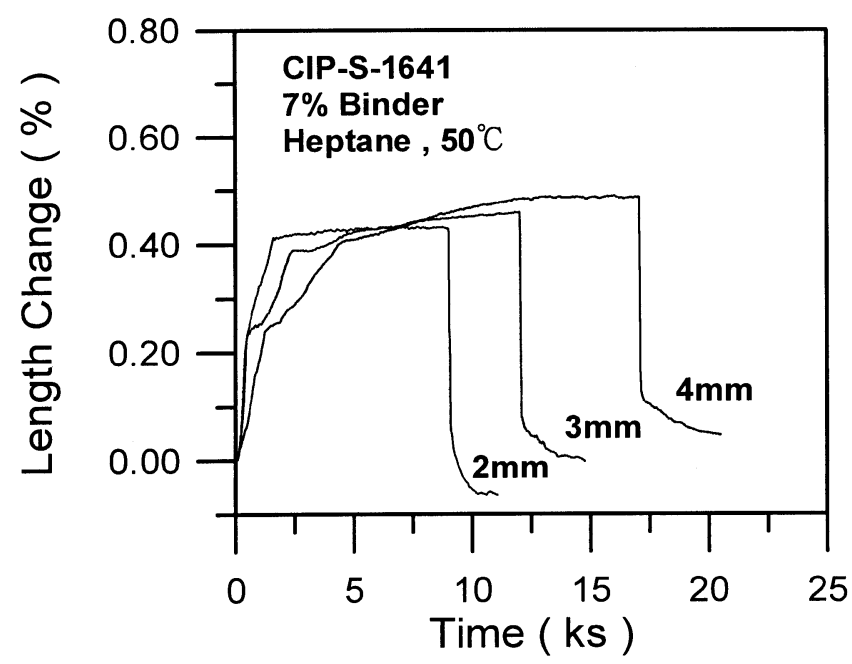

Fig. 8-The amount of expansion varies with the cross-sectional thickness of the specimen, particularly in the early stage.

and distortion still occur, particular in complex-shaped parts with overhung sections. Figure 9 shows the effect of the debinding temperature on the in-situ sagging distance of compacts during solvent debinding. The amount of sagging increased as the temperature increased, similar to that observed in Figure 5 on the length changes. This is expected, because the binder strength decreased with the increase of the temperature.

To further understand the influence of soluble binders on the deformation behavior of compacts during solvent debinding, the in-situ sagging distance of the specimen in which 90 pct of the soluble binders had been removed was measured. Figure 10 shows that, as the specimen was immersed in heptane at $27^{\circ} \mathrm{C}$, the sagging curve reached a plateau of about $310 \mu \mathrm{m}$ in $0.2 \mathrm{ks}$. As the temperature increased, the amount of sagging increased, particularly at $50{ }^{\circ} \mathrm{C}$ and $55^{\circ} \mathrm{C}$. Comparing Figures 9 and 10 , it is clear that the amount of sagging is about the same for both specimens, with or without soluble binders. This indicates that

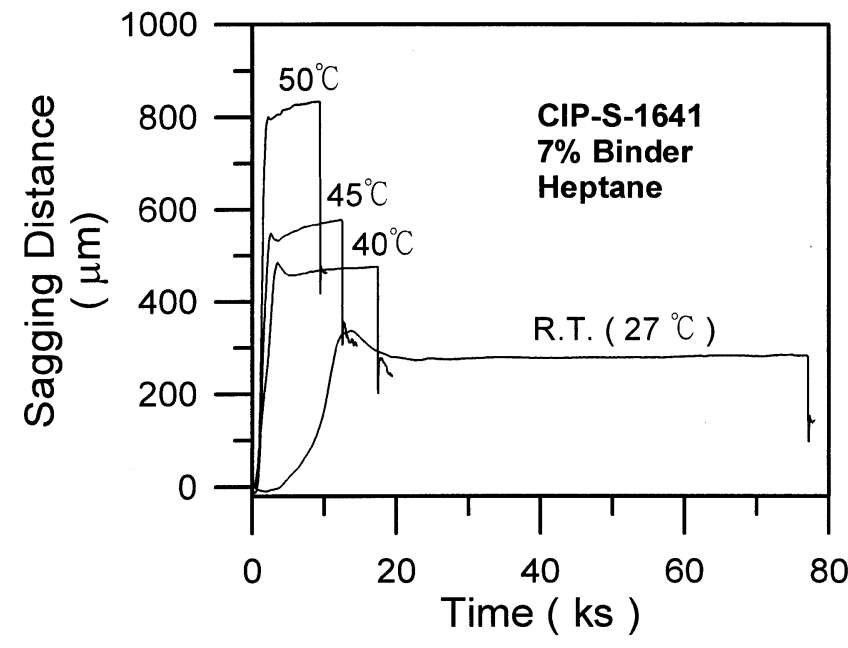

Fig. 9-The in-situ sagging distance of specimens containing 7 wt pct binder during solvent debinding at different temperatures.

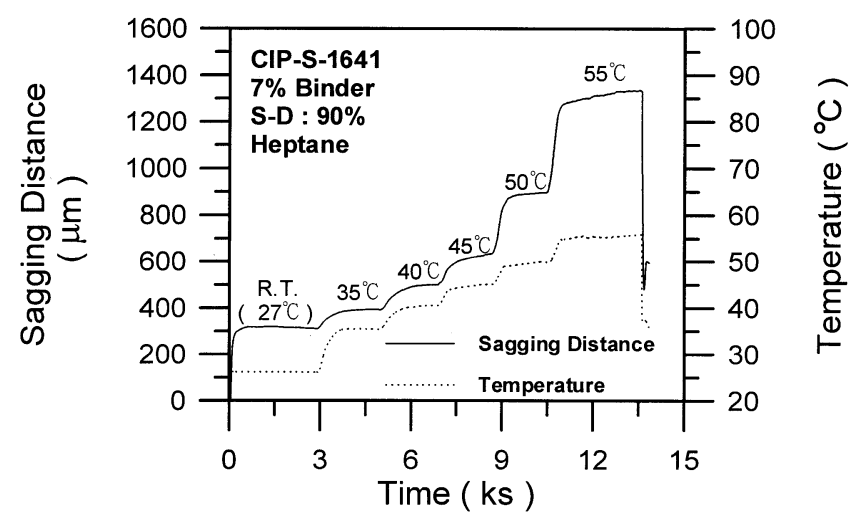

Fig. 10-The effect of the temperature on the sagging distance of the specimen in which 90 pct of the soluble binders had been extracted.

the strength of the compact is determined mainly by the insoluble binder, LDPE. The take-away temperature of 50 ${ }^{\circ} \mathrm{C}$, which is much lower than the melting point of the LDPE, also indicates that a reaction between heptane and LDPE caused softening of the compact.

Figure 11 shows the effect of the binder content and the debinding temperature on the amount of sagging, for compacts in which 90 pct of the soluble binders had been removed. All curves show that the amount of sagging increased with the increase of the debinding temperature. The curves deflected with a steeper slope when the temperature was greater than $50{ }^{\circ} \mathrm{C}$. The same deflection point on all three curves indicated that the softening point is governed by the composition of the binder. It is also notable that less sagging occurred as the binder content increased. This means that the backbone binder, LDPE in this case, is the one contributing most to the strength of the specimen during solvent debinding, not the metal-powder content.

\section{DISCUSSION}

The previous results suggest that there are three factors causing the swelling of PIM compacts during solvent debinding: (1) thermal expansion, (2) dissolution of soluble binders 


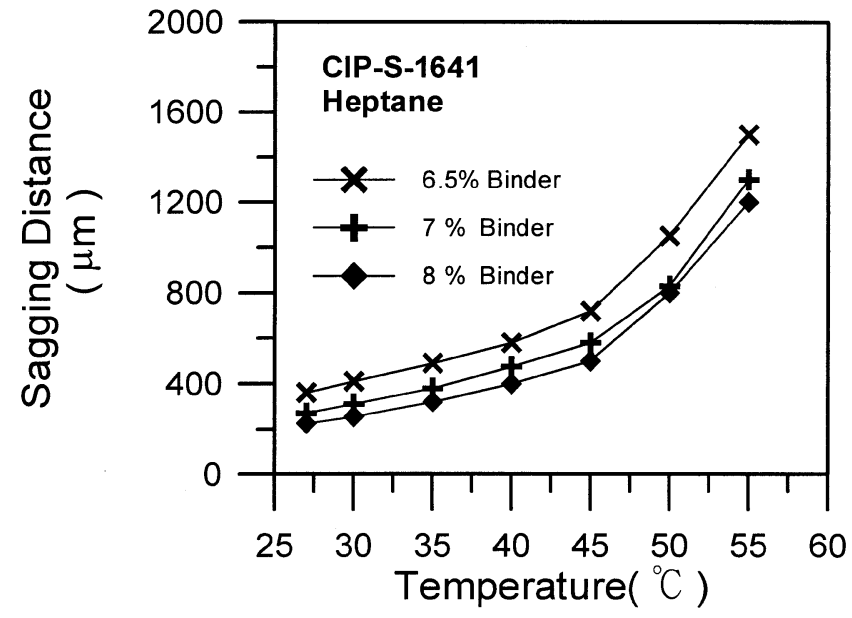

Fig. 11-The effects of the solvent debinding temperature and the binder content on the amount of sagging distance for compacts in which 90 pct of the soluble binders had been removed.

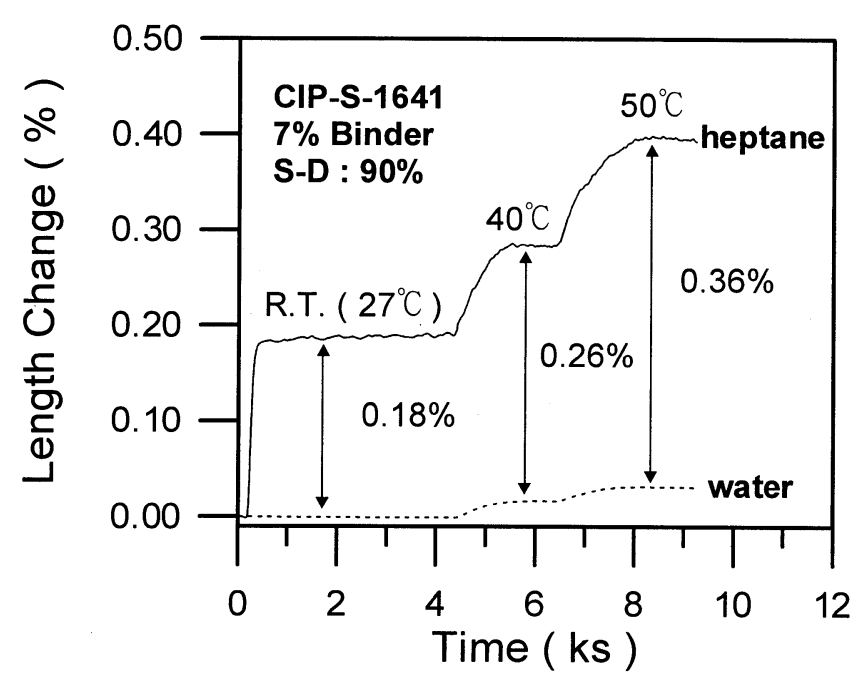

Fig. 12-The length changes of solvent-debound specimens when immersed in water and in heptane, respectively.

into heptane, and (3) interaction between insoluble binders and heptane.

\section{A. Thermal Expansion}

Figures 4 and 6 show that the initial stage of the swelling increases linearly with the temperature, due to the thermalexpansion effect. The CTE of the compact, calculated from Figure 3 , is $116 \times 10^{-6} \mathrm{~m} / \mathrm{m} / \mathrm{K}$. It matches well with the value of $119 \times 10^{-6} \mathrm{~m} / \mathrm{m} / \mathrm{K}$, which is calculated from the CTEs of the mixed binder and the iron, using the rule of mixtures. This CTE, however, decreases significantly during solvent debinding because $\mathrm{PW}$, which has a high CTE of $395 \times 10^{-6} \mathrm{~m} / \mathrm{m} / \mathrm{K}$, continuously dissolves into heptane. To demonstrate this effect, compacts in which 90 pct of the soluble binder had been removed were immersed in heptane and water, respectively. Figure 12 shows that, as the water temperature increased from $27{ }^{\circ} \mathrm{C}$ to $40{ }^{\circ} \mathrm{C}$, the specimen expanded by 0.017 pct. This means that the CTE decreased to $13 \times 10^{-6} \mathrm{~m} / \mathrm{m} / \mathrm{K}$ due to the loss of $\mathrm{PW}$.

\section{B. Swelling by an Insoluble Binder}

After deducting the amount of thermal expansion that was measured in water, it is seen in Figure 12 that the specimen expanded 0.18 pct at $27{ }^{\circ} \mathrm{C}, 0.26$ pct at $40{ }^{\circ} \mathrm{C}$, and 0.36 pct at $50{ }^{\circ} \mathrm{C}$. Since there was very little soluble binder in the compact, these expansions were caused mainly by the swelling effect of the insoluble binder of LDPE. A comparison between these values and those shown in Figure 5 for asmolded compacts also indicates that the swelling of the insoluble binder accounts for the major portion of the expansion in the early stage of debinding.

\section{Swelling by Soluble Binders}

Figures 4 to 7 show that a peak formed at the front section of the swelling curve. The height of the peak increased as the debinding temperature decreased, as was illustrated in Figure 5. Since the peak disappeared as the debinding time increased, this peak must be related to the binder, which is soluble in heptane. Lin and Hwang reported that, as the pure soluble-binder components, (PW and SA) were dissolved into heptane, the total volume of the solution increased. ${ }^{[13]}$ It is postulated that these soluble binders, when dissolved into heptane, form an expanded solution inside the swollen LDPE gel. If the out-diffusion rate of the solution is slow, as at low temperatures, expansion stress could then be exerted by the swelling solution, resulting in an additional amount of expansion and, thus, forming a peak at the early stage of debinding. If the expanding stress is high enough, cracking may even occur. As the debinding time increases, the solution slowly diffuses out, and the peak then starts to fall. As the debinding temperature increases, the diffusion rate of the solution becomes faster. The peak then becomes less noticeable.

The aforementioned three factors-thermal expansion, dissolution of soluble binders into heptane, and interaction between insoluble binders and heptane-are the main causes of swelling during solvent debinding. The total amount of the expansion is, however, not necessarily the sum of those from each contributing factor. For example, as the temperature increased from $27{ }^{\circ} \mathrm{C}$ to $40{ }^{\circ} \mathrm{C}$, the thermal expansion measured was 0.15 pct. The amount of expansion caused by insoluble LDPE is about 0.26 pct, as was shown in Figure 12. The sum of these two numbers, without taking into account the factor caused by soluble binders, is already much larger than the value of 0.31 pct shown in Figure 5.

\section{Sagging, Distortion, and Tolerance Control}

One of the main advantages of the powder injection molding process is that complex-shaped parts can be produced with little machining. This also implies that some sections in the part could extend out, without any support, and may sag or distort during debinding and sintering. The results in Figures 9 and 10 show that the as-molded and solventdebound specimens sagged significantly in $50{ }^{\circ} \mathrm{C}$ heptane. This softening point of $50{ }^{\circ} \mathrm{C}$ is much lower than the melting point $\left(98^{\circ} \mathrm{C}\right)$ of LDPE in the feedstock, as was measured by the DSC test. This interaction of the solvent-polymer is also indicated by the swelling of the LDPE when the compact was immersed in heptane, a phenomenon not occurring when the compact was immersed in water, as shown in Figure 


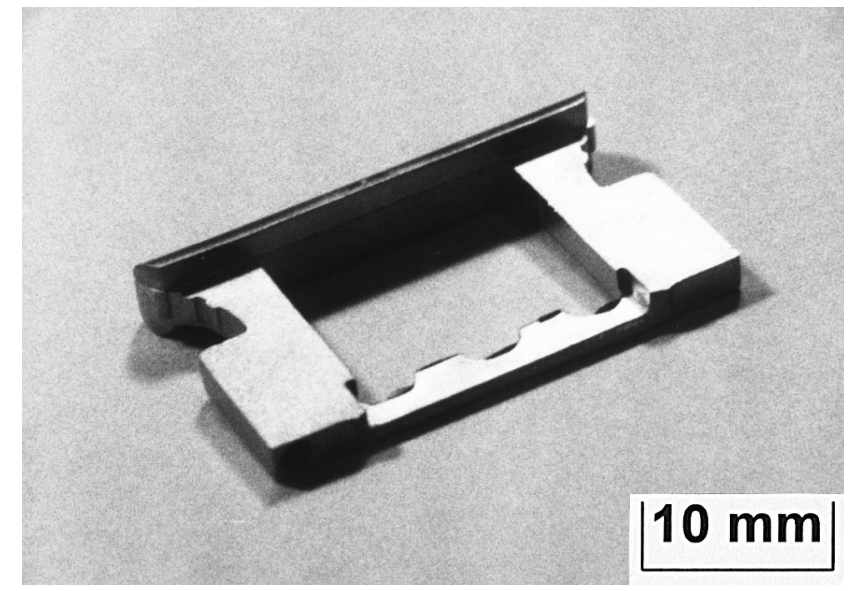

Fig. 13-A PIM compact with different cross-sectional thickness on the four sides is susceptible to distortion during solvent debinding.

12. Although the debinding rate increases as the debinding temperature rises, the distortion and slumping of compacts should also be considered. Thus, the optimum debinding temperature selected in this study was $45^{\circ} \mathrm{C}$.

It was also found, as shown in Figure 11, that the amount of sagging decreased as the binder content increased. This result contradicts the previously held belief that the shaperetention capability decreases as the amount of binder in the compact increases. This, however, does not necessarily mean that more binder should be added into the feedstock; doing so may cause adverse effects during the subsequent thermal debinding and sintering. More-detailed studies are needed to find the optimum binder content.

The previous results have shown that a significant amount of expansion occurs during solvent debinding. The amount of expansion depends on the binder content of the compact. Since PIM parts usually have complex shapes, a nonuniform green-density or binder content in the compact is frequently encountered due to the poor flow of the feedstock in the mold cavity. With variations of the binder content in the compact, anisotropic expansion and/or distortion could then occur. The amount of expansion also depends on the thickness of the compact. Figure 13 shows a sample with different thicknesses on the four sides. Since the thin section swells at a faster rate than the thick section, as was demonstrated in Figure 8, a stress was exerted on the thin section. Due to the uneven amount of expansion of the four sides, distortion occurred. Thus, uniform thickness should always be considered when designing a PIM part. If it is impossible to maintain uniform thickness, a lower debinding temperature should be used, along with a binder and a solvent that will cause less expansion to alleviate the problem. Since the PW is the component with the highest CTE, another approach is to use a PW which has a lower CTE. This should help to decrease the thermal expansion, which occurs during heating in the solvent bath. It will also help decrease the amount of shrinkage that usually occurs after the mold release during injection molding.

\section{CONCLUSIONS}

A laser dilatometer was setup in this study to measure the in-situ length change and the sagging distance of PIM compacts during solvent debinding. Expansion on the compact was found and was caused by three factors: (1) thermal expansion, (2) dissolution of soluble binder into the solvent, and (3) reaction between the insoluble binder and the solvent.

The total amount of expansion increases with an increase in the debinding temperature and the binder content. The thickness also affects the expansion rate and could cause distortion in compacts which have different cross-sectional thicknesses.

The sagging test indicated that the strength of the compact is governed by the binder content. As the temperature increases, the sagging distance of the compact increases, particularly at temperatures of $50{ }^{\circ} \mathrm{C}$ and higher. This softening point, which is still lower than the melting point of the backbone binder, should be chosen as the upper limit of the debinding temperature.

These in-situ measurements on the length change and the sagging distance help explain the cause of slumping, cracking, and distortion formed during solvent debinding. With an understanding of these results, some guidelines are provided in selecting debinding parameters and in designing the binder systems.

\section{ACKNOWLEDGMENTS}

The authors thank the National Science Council of the Republic of China for their support of this work under Contract No. NSC 87-2216-E-002-033.

\section{REFERENCES}

1. K.P. Johnson: U.S. Patent No. 4,765,950, 1988.

2. R.E. Wiech, Jr.: U.S. Patent No. 4,197,118, 1980.

3. R.M. German: Powder Injection Molding, Metal Powder Industries Federation, Princeton, NJ, 1990, pp. 321-46.

4. K.S. Hwang: Rev. Part. Mater, 1996, vol. 4, pp. 71-104.

5. R.M. German and A. Bose: Injection Molding of Metals and Ceramics, Metal Powder Industries Federation, Princeton, NJ, 1997, pp. 175-218.

6. K.S. Hwang and Y.M. Hsieh: Metall. Mater. Trans. A, 1996, vol. 27A, pp. 245-53.

7. S.T. Lin and R.M. German: Powder Metall. Int., 1989, vol. 21 (5), pp. 19-24.

8. H.E. Amaya: in Advances in Powder Metallurgy and Particulate Materials-1991, E.R. Andreotti and P.J. McGeehan, eds., Metal Powder Industries Federation, Princeton, NJ, 1991, vol. 1, pp. 233-46.

9. D.S. Tsai and W.W. Chen: Ceram. Int., 1995, vol. 21, pp. 257-64.

10. S.C. Hu and K.S. Hwang: P/M Science and Technology Briefs, 1999, vol. 1 (2), pp. 27-30.

11. N.F. Liau and S.T. Lin: Mater. Manufacturing Processes, 1997, vol. 12(24), pp. 661-71.

12. F.W. Billmeyer, Jr.: Textbook of Polymer Science, John Wiley and Sons, Inc., New York, NY, 1984, pp. 151-52.

13. H.K. Lin and K.S. Hwang: Acta Mater., 1998, vol. 46 (12), pp. 4303-09. 